\title{
Cardiovascular effects of a saponin from Albizzia chinensis
}

\author{
Naresh Gupta ${ }^{1}$, Dinesh Kansal ${ }^{2 *}$, Anjna Sharma ${ }^{3}$ \\ ${ }^{1}$ Associate Professor, ${ }^{2}$ Professor and HOD, ${ }^{3}$ Tutor, Dept. of Pharmacology, ${ }^{1,3}$ Dr. Radhakrishnan Government Medical College Hamirpur, \\ Himachal Pradesh, ${ }^{2}$ Dr. Rajendra Prasad Government Medical College, Tanda, Himachal Pradesh, India

\section{*Corresponding Author: Dinesh Kansal} \\ Email: dinesh.kansal56@gmail.com
}

\begin{abstract}
Introduction: The cardio-vascular system being the basis of life along with the respiratory system has always been the centre of attention for researchers. Efforts have been made for ages to prop up the failing heart or to regulate its normal beat \& rhythm so that life could be extended. A major source of drugs for the heart is the plant kingdom. With this in mind a saponin from a plant called Albizzia chinensis Merr. was taken up to profile its cardiovascular activities.

Materials and Methods: Albichinoside (ALB), the test substance was evaluated for its cardio-vascular activities in dogs, rabbits, rats and frogs. The parameters were its effects on the rate, rhythm and tone of heart, blood pressure and studies on the blood vessels.

Results: The test substance produced hypotension, increase in tone \& force of contraction of the heart, and dilatation of the blood vessels, without any effect on the heart rate.

Conclusions: The compound showed immediate and prolonged hypotension along with cardiotonic effect and vasodilatation.
\end{abstract}

Keywords: Saponin, Cardiovascular system, Animals.

\section{Introduction}

Plants are a major source of drugs for us. Since the evolution of human species various ailments have always been causing agony and problems to us. But the superior development of our brain has allowed us to use things available naturally to ameliorate these day to day problems. Since plants were abundant and a wide variety of them was available, they were our first source of remedies. Over the years the active constituents were identified and there are so many of them. Out of them saponins hold promise, besides the others, but they have not been thoroughly studied. A pure saponin fraction albichinoside (ALB) was taken up for the present study. It was obtained from the bark and heart wood of the plant Albizzia chinensis occurring in tea plantations in Kangra District of Himachal Pradesh.

\section{Plan of Study}

The test compound albichinoside was evaluated for its effects on the cardiovascular system in frogs, rabbits, rats and dogs. The parameters for the study included effects on the heart rate (HR), blood pressure (BP), tone and blood vessels.

\section{Materials and Methods}

The cardiovascular (CVS) effects of the test compounds were studied in frogs, rabbits, rats and dogs. The animals used in the experiments were housed in cages which were kept in clean and airy rooms. Artificial heating was used to keep them warm in the harsh winter weather. They were fed on suitable nutritious food. Water was made available freely. The average weight of frogs was 100-300 gms, rats 100-225 gms, rabbits 700-1000 gms and dogs 5-15 kgs. Animals of the same strain but of any sex were used for the experiments.

The solutions used for the experiments were Normal Saline ( $0.9 \%$ sodium chloride), Frog's Ringer and Ringer.
The drugs used included pentobarbitone sodium $(35.0$ $\mathrm{mg} / \mathrm{kg}$ ), heparin $1 \%$ solution, sodium citrate $10 \%$, adrenaline $(2 \mu \mathrm{g} / \mathrm{kg} \mathrm{BW})$, nor adrenaline $(2 \mu \mathrm{g} / \mathrm{kg} \mathrm{BW})$, acetylcholine $(2 \mu \mathrm{g} / \mathrm{kg} \mathrm{BW})$, carbachol $(0.2 \mu \mathrm{g} / \mathrm{kg} \mathrm{BW})$, histamine $(2 \mu \mathrm{g} / \mathrm{kg}$ BW), nicotine $(50 \mu \mathrm{g} / \mathrm{kg}$ BW), albichinoside (5.0 mg/kg BW), propranolol $(20 \mu \mathrm{g} / \mathrm{kg} \mathrm{BW}$ and isoprenaline $(2 \mu \mathrm{g} / \mathrm{kg} \mathrm{BW})$. Stock solutions of the drugs used were prepared in distilled water. Wherever required the final dilution was made in normal saline before use. The test substance was albichinoside (ALB).

\section{Blood Pressure Studies}

Effects on Blood Pressure of Anaesthetized Dog (Jackson, $1939 a)^{1}$

A healthy mongrel dog was anaesthetized with pentobarbitone sodium $(35 \mathrm{mg} / \mathrm{kg})$ i.p and mounted on the dog experiment table and secured firmly to it. The femoral vein was then dissected out and cannulated with a venous cannula which was connected to a burette containing $0.9 \%$ sodium chloride solution, by rubber tubing. Tracheotomy was then done and a tracheal cannula was inserted. The common carotid arteries were then identified and isolated. The right carotid artery was then ligated near the site of its branching and an arterial cannula was inserted into it after filling the bulb with $0.5 \mathrm{ml}$ of $1 \%$ heparin solution and taking care to remove all air bubbles from the sodium citrate tube. The cannula was then connected to the mercury manometer one of whose limbs was connected to a bottle containing $10 \%$ sodium citrate. Before removing the artery forceps from the tube, the pressure in the manometer was raised to $120 \mathrm{~mm}$ of $\mathrm{Hg}$. The normal blood pressure was recorded and the heart rate was taken. The following drugs were then injected in sequence in the rubber tubing attached to the venous cannula and $5 \mathrm{ml}$ of saline was run after each drug and the recordings of the blood pressure were taken. The heart-rate after each drug was also recorded. 
1. Adrenaline $(2 \mu \mathrm{g} / \mathrm{kg}$ of body weight).

2. Nor-adrenaline $(2 \mu \mathrm{g} / \mathrm{kg}$ of body weight).

3. Acetylcholine $(2 \mu \mathrm{g} / \mathrm{kg}$ of body weight).

4. Carbachol $(0.2 \mu \mathrm{g} / \mathrm{kg}$ of body weight).

5. Histamine $(2 \mu \mathrm{g} / \mathrm{kg}$ of body weight $)$.

6. Nicotine $(50 \mu \mathrm{g} / \mathrm{kg}$ of body weight).

The aqueous solution of albichinoside $(5.0 \mathrm{mg} / \mathrm{kg})$ was then injected similarly and the blood pressure and the heartrate were recorded.

The effect of carotid occlusion was observed by first taking the normal response to it, and then giving the test compound. After sometime the above drugs and or maneuvers were again repeated to observe changes, if any.

\section{Studies on the Heart \\ Perfused Frog Heart (Burn, 1952). ${ }^{2}$}

Healthy, medium sized frogs were used for this experiment. The frog was pithed and the heart was exposed. The pericardium was removed and a venous cannula was inserted into the inferior vena cava. The cannula was connected to a perfusion bottle containing Frog's Ringer. One aorta was cut to provide an outlet for the perfusion fluid. A hook was passed through the tip of the ventricle and its other end was connected to the Starling's heart lever. The contractions were recorded on the Sherrington's electrically operated kymograph.

Responses with adrenaline $(2 \mu \mathrm{g})$ and acetylcholine $(2 \mu \mathrm{g})$ were recorded. The drugs were injected through the rubber tubing attached to the venous cannula. Albichinoside was then injected in increasing doses $(10,20,40,80,160$, $320 \mu \mathrm{g}$ ) and the response on the rate, rhythm, tone and the force of the heart was recorded.

Effect of Propranolol on the Stimulant Effect of Albichinoside on the Frog Heart: A frog was set up as usual on the frog board. Responses were taken with adrenaline $((2 \mu \mathrm{g})$ and Isoprenaline $(2 \mu \mathrm{g})$. Then the response with $320 \mu \mathrm{g}$ of albichinoside was taken. After the heart returned to normal $20 \mu \mathrm{g}$ of propranolol was injected. After some time adrenaline $(2 \mu \mathrm{g})$ was given. Again the same dose of propranolol was given and a little later the earlier dose of albichinoside was administered. Increasing doses of propranolol $(40 \mu \mathrm{g}, 80 \mu \mathrm{g})$ were given and the effect on the response to albichinoside $(320 \mu \mathrm{g})$ was observed.

Effect of Albichinoside on the Atropinized Frog Heart: A frog was mounted as usual and the response to acetylcholine $(2 \mu \mathrm{g})$ was taken. Then atropine sulphate $(20$ $\mu \mathrm{g}$ ) was administered and after 10 minutes the same dose of acetylcholine was given. Then albichinoside was given in a dose of $320 \mu \mathrm{g}$ and the response was recorded.

Effect on Isolated Perfused Rabbit Heart (Lagendroff, 1885). ${ }^{3}$

A rabbit was killed by a blow on head. The chest was opened and heart was carefully removed. It was then immediately dipped into Ringer's solution which was maintained at $37{ }^{\circ} \mathrm{C}$ and gently squeezed to remove blood from the aorta. A cannula was then tied in the aorta.

The other end of the cannula was tied through rubber tubing to an apparatus essentially designed to deliver oxygenated Ringer's solution at a constant head of pressure and a constant temperature $\left(37^{\circ} \mathrm{C}\right)$. When the whole set up was ready, a small hook was fixed in the tip of the ventricle and the perfusion was then began, taking care that no bubbles entered the aorta.

A record was obtained of the amplitude of the ventricular contractions. The contractions were observed until they ceased to change. Injections of the drugs were made by a syringe through the rubber tube on the side arm of the cannula tied in the aorta. Rate of beating and the amplitude of the contractions were recorded.

The effect of propranolol on the effect of albichinoside was also studied.

\section{Effect on Dog's Heart in Situ (Burn,1952) ${ }^{2}$}

A dog was set up on the operation table and secured firmly after injecting the anaesthetic, pentobarbital sodium $(35.0 \mathrm{mg} / \mathrm{kg})$. The femoral vein was dissected out and a venous cannula was introduced into it. It was connected to a burette containing normal saline. Trachea was then exposed and cannulated. The dog was kept under forced respiration with a respiratory pump.

The thorax was opened by removing the anterior portion of the left fourth rib. Heart was exposed by slitting open the pericardium. Pre-heated $\left(37^{\circ} \mathrm{C}\right)$ normal saline was filled in the chest cavity. The ventricular contractions were recorded by fixing a small hook in the tip of the ventricle. A thread was connected to the hook and after passing it through a swivel pulley it was tied to a straw lever.

From time to time normal saline $\left(37^{\circ} \mathrm{C}\right)$ was poured in the chest cavity. The normal contractions were observed till they stabilized. The test compounds were then injected into the femoral vein and the effects were recorded. When the contractions were again normal, increasing doses of the test compound were given and the effects recorded. The effects of prior administration of propranolol on the response of the drug were also studied.

\section{Studies on the Blood Vessels}

Frog Hind Limb Perfusion (Burn, 1952). ${ }^{2}$ A Frog was pithed and the lower abdominal cavity was carefully exposed. The mesenteric arteries were divided between ligatures and the rectum was cut off so as to expose the dorsal aorta and renal portal veins. The frog was then fixed on a frog board.

The dorsal aorta was cannulated. Other end of the cannula was connected to an aspirator bottle containing $0.6 \%$ saline solution with a device to maintain a constant pressure head. Both the left and right portal veins were cut to allow free flow of the out coming liquid. This liquid was made to drain through a cotton pad and the drops were allowed to fall on a lever. The rate of perfusion was adjusted to 30-40 drops per minutes.

When the normal perfusion stabilized, repeated doses of test compound were injected through the rubber tubing of the perfusion fluid, near the cannula. The number of drops per minute was counted after the drug injection. The effect of prior administration of propranolol on the flow rate was also studied. 
Rat Hind Limb Perfusion (Burn, 1952). ${ }^{2}$ A rat was killed and its abdominal cavity was opened. The abdominal aorta was exposed and a cannula was tied in it. The other end of the cannula was connected to an aspirator bottle containing Ringer solution.

The clip was released and the flow of the perfusion fluid was regulated by altering the height of perfusion fluid.

Increasing doses of test compound were then administrated near the cannula and the resulting change in the flow of perfusion fluid was recorded. For each dose the numbers of drops per minute were counted. The effect of prior administration of propranolol on the flow rate response of albichinoside was also studied.

\section{Observations and Results}

Effect on the Blood Pressure of Anesthetized Dog: The compound in a dose of $5.0 \mathrm{mg} / \mathrm{kg}$ produced an immediate fall in blood pressure by $20 \mathrm{~mm}$ of $\mathrm{Hg}$. from $120 \mathrm{~mm}$ of $\mathrm{Hg}$ (control) to $100 \mathrm{~mm}$ of $\mathrm{Hg}$. The effect lasted for about 3.5 minutes. The recovery was not complete and the bloods pressure stabilized at $110 \mathrm{~mm}$ of $\mathrm{Hg}$.

The intra-carotid administration of the drug produced delayed hypotensive response.

The drug did not affect the response on the blood pressure produced by nicotine, carotid occlusion, adrenaline, nor-adrenaline, acetylcholine, isoprenaline and histamine (Fig. 1).

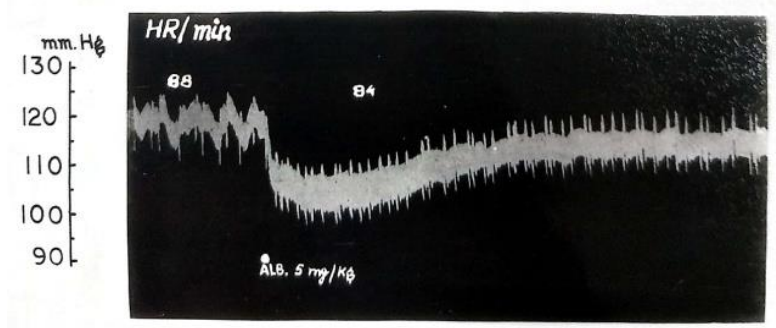

Fig. 1: Effect of albichinoside (ALB) on the blood pressure of the anaesthetized dog.

\section{Effect on Heart}

Isolated Perfused Frog Heart: The compound produced an increase in the force of contraction and tone of the heart without affecting the heart rate in doses of 10, 20, 40, 80 and $160 \mu \mathrm{g}$. In a dose of $320 \mu \mathrm{g}$, the tone increased and the heart stopped in systole. High doses of propranolol up to 80 $\mu \mathrm{g}$ did not block the response. Similar effects were observed in the previously atropinized heart (Fig. 2).

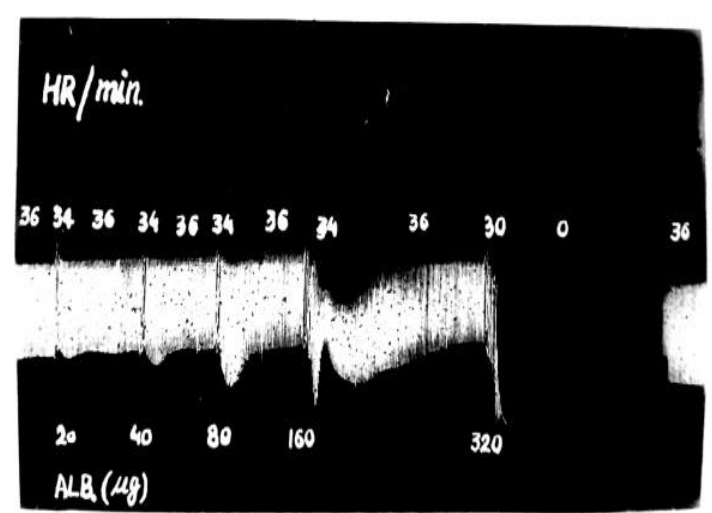

Fig. 2: Effect of albichinoside on the isolated perfused frog heart

Dog Heart in Situ: The drug caused an increase in the force of contraction and tone of the heart with the heart rate remaining unaffected (Fig. 3).

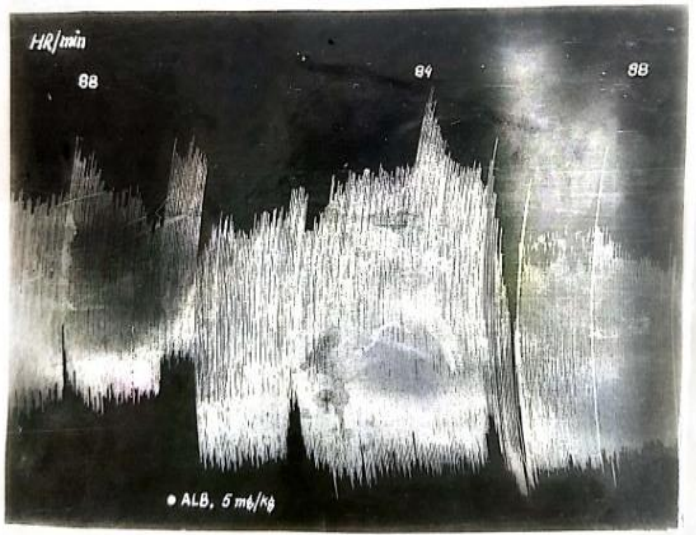

Fig. 3: Effect of albichinoside on the heart in situ of the anaesthetized dog

Isolated Rabbit Heart: Administration of albichinoside $(320 \mu \mathrm{g})$ caused an increase in the tone of the heart. The heart rate was unaffected (Fig. 4).

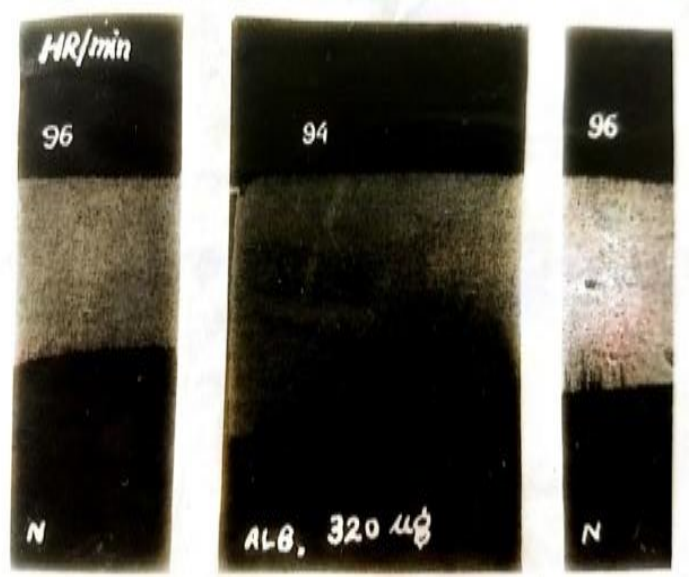

Fig. 4. Effect of albichinoside on the isolated rabbit heart 
Effect on Blood Vessels

Frog Hind Limb Perfusion: The drug caused an increase in the flow rate as depicted by the increase in number of drops of the out coming fluid recorded per minute. Prior administration of propranolol had no effect on the response (Table 1).

Table 1: Effect of albichinoside on the blood vessels by the frog hind limb perfusion method

\begin{tabular}{|l|c|c|c|c|c|c|}
\hline \multirow{2}{*}{ Drug } & \multirow{2}{*}{ Dose } & Drops/min. & \multicolumn{4}{|c|}{ Drops/min after drug at different intervals (minutes) } \\
\cline { 4 - 7 } & & before drug & $\mathbf{3}$ & $\mathbf{5}$ & $\mathbf{1 0}$ & $\mathbf{1 5}$ \\
\hline Control (Vehicle) & - & 56 & 58 & 56 & 60 & 55 \\
\hline Albichinoside & 5.0 & 58 & 70 & 75 & 78 & 75 \\
\hline
\end{tabular}

Rat Hind Limb Perfusion: The compound increased the flow of the out coming perfusion fluid as determined by the increase in number of drops recorded per minute. Prior administration of propranolol had no effect on the flow (Table 2).

Table 2: Effect of albichinoside on the blood vessels by the rat hind limb perfusion method

\begin{tabular}{|l|c|c|c|c|c|c|}
\hline Drug & \multirow{2}{*}{ Dose } & \multirow{2}{*}{ Drops/min } & \multicolumn{4}{|c|}{ Drops/min after drug at different intervals (minutes) } \\
\cline { 1 - 4 } & & & $\mathbf{3}$ & $\mathbf{5}$ & $\mathbf{1 0}$ & $\mathbf{1 5}$ \\
\hline Control (Vehicle) & - & 30 & 29 & 28 & 30 & 29 \\
\hline Albichinoside & 5.0 & 30 & 55 & 55 & 56 & 58 \\
\hline
\end{tabular}

\section{Conclusions}

1. Albichinoside produced a fall in blood pressure in the anaesthetized dog. The onset was quick and the duration of action was slightly prolonged. The blood pressure did not return to the normal level. It further increased the tone of cardiac muscle in heart in situ. The compound did not produce any significant effect on either the heart rate or the respiration.

2. In isolated heart, the compound increased the tone of cardiac muscle without having any effect on the cardiac rate. The effect was dose dependent and in high doses the heart stopped in systole.

3. Albichinoside produced dilatation of blood vessels.

\section{Summary}

The test substance produced an immediate and prolonged hypotensive effect in anaesthetized dogs which seems to be due to central nervous depression and direct vasodilatation as it was also found to dilate blood vessels. The respiration was not affected.

The saponins showed cardiotonic activity in the isolated frog and rabbit heart and the dog heart in situ, which was not blocked by propranolol. There was no effect on the heart rate which suggests that their effect is not mediated through the beta $(\beta)$ adrenergic receptors.

\section{References}

1. Jackson, D.E. (1939a). In: Experimental Pharmacology and Materia Medica. 2nd Ed. 163. London, C.V. Mosby and Co. Ltd.

2. Burn, J.H. (1952). In: Pract. Pharmacol. Ed.I. Oxford: Blackwell Sci. Pub. Ltd.

3. Lagendorff, O. Arch. Gen Physiol. 1885;8:284.

How to cite this article: Gupta N, Kansal D,
Sharma A. Cardiovascular effects of a saponin from
Albizzia chinensis. Indian J Pharm Pharmacol.
2018;5(4):187-190.

